\title{
ANÁLISE DAS DIFICULDADES ENFRENTADAS EM ALGUMAS ESCOLAS NA IMPLEMENTAÇÃO DA GESTÃO DEMOCRÁTICA
}

\author{
Diego de Vargas Matos ${ }^{1}$
}

\begin{abstract}
Resumo: Este artigo objetiva analisar as dificuldades enfrentadas por alguns gestores na implementação da gestão democrática nas escolas onde atuam. Para tanto, foi desenvolvida uma pesquisa de abordagem qualitativa, envolvendo um estudo de caso. A coleta de dados foi realizada por meio de questionários respondidos por dez gestores escolares das redes municipal e estadual de ensino do Rio Grande do Sul. Os dados coletados foram analisados por meio da Análise Textual Discursiva (ATD), perfazendo todas as suas etapas: unitarização; categorização; comunicação das novas compreensôes atingidas - metatexto. A análise evidencia que as dificuldades enfrentadas pelos gestores, sujeitos desta pesquisa, na implementação da gestão democrática nas escolas onde atuam são a falta de participação da comunidade escolar nas tomadas de decisóes referentes à escola, a falta de autonomia da escola devido à hierarquização da gestão educacional e a falta de atualização nas práticas pedagógicas dos professores e gestores.
\end{abstract}

Palavras-chave: Gestão Escolar Democrática. Comunidade Escolar. Dificuldades.

\section{ANALYSIS OF THE DIFFICULTIES FACED IN SOME SCHOOLS IN THE IMPLEMENTATION OF DEMOCRATIC MANAGEMENT}

\begin{abstract}
This project main object is to analyze the difficulties of some managers in the implementation of democratic management in the schools where they work. Therefore, was developed a qualitative approach research, which involved a case study. A date collection was made through questionnaires answered by ten school managers of public schools of Rio Grande do Sul. The data collected were analyzed by means of Discursive Textual Analysis, completing all of steps: unitarization, categorization, communication of the new understandings reached. The analysis shows that the difficulties encountered by the managers, subjects of this research, are the lack of school community participation, lack of school autonomy due to the hierarchy of educational management and the lack of updating in pedagogical practices of teachers and managers.
\end{abstract}

1 Mestre em Educação em Ciências e Matemática pela PUCRS, Especialista em Docência no Ensino Superior e em Gestão Escolar pela UNIASSELVI, Licenciado em Matemática pela PUCRS e Licenciando em Pedagogia pela UNIASSELVI. Atualmente, leciona a disciplina de Matemática na Educação Básica das redes municipais de ensino de Alvorada e Viamão, RS. E-mail: diego.matos@acad.pucrs.br 
Key words: Democratic school management. School community. Difficulties.

\section{INTRODUÇÃO}

Conforme é possível verificar em dicionários, gestão trata-se do exercício da pessoa responsável pela administração, seja de escolas, de empresas, dentre outras (DICIO, 2020). Entretanto, segundo Paro (1988), a administração escolar se difere da administraçáo de empresas no sentido de que a primeira preocupa-se com o acesso ao conhecimento, enquanto a segunda busca acumular capital adquirido com a mão de obra trabalhadora.

É válido também destacar que a gestão não é responsabilidade de apenas um profissional, pois necessita das habilidades de diferentes pessoas. Cada profissional tem o seu perfil que pode estar adequado à liderança em uma função ou situação, mas não em outra, segundo Minicucci (2001). Assim, considera-se a gestão um exercício que deve ser compartilhado com várias pessoas, o que deve ocorrer também nas escolas.

Nesse sentido, surge a necessidade de realizar esta pesquisa sobre o tema Gestão Escolar Democrática, uma vez que também é indicado em documentos legais elaborados pelo Ministério da Educação (MEC). O objetivo deste estudo é analisar as dificuldades enfrentadas por alguns gestores na implementação da gestão democrática nas escolas onde atuam. Alcançar esse objetivo equivale a responder: Quais são as dificuldades enfrentadas por alguns gestores na implementação da gestáo democrática nas escolas onde atuam?

Para tanto, algumas metas foram elencadas. São elas: da área;

a) Verificar conceitos de gestão escolar democrática apresentados na literatura

b) Apresentar modos que possibilitem a gestáo escolar democrática de acordo com a legislação educacional brasileira;

c) Identificar dificuldades enfrentadas por alguns gestores na implementação da gestão democrática nas escolas onde atuam.

Para o alcance dessas metas, foi desenvolvida esta pesquisa de abordagem qualitativa, a qual envolve um estudo de caso. A coleta de dados foi realizada por meio de questionários respondidos por dez gestores escolares das redes municipal e estadual de ensino do Rio Grande do Sul. Os dados coletados foram analisados por meio da Análise Textual Discursiva (ATD), defendida por Moraes e Galiazzi (2011), perfazendo todas as suas etapas: unitarização; categorização; comunicação das novas compreensóes atingidas - metatexto.

Espera-se que, com os resultados obtidos nesta investigaçáo, seja possível conscientizar os profissionais da educação sobre a importância da gestáo democrática para a escola e deixá-los cientes das dificuldades que podem ser encontradas ao buscar a implementação dessa modalidade de gestão escolar. 


\title{
2 ALGUNS APORTES TEÓRICOS E LEGAIS
}

\subsection{SOBRE A FORMAÇÃO DO GESTOR ESCOLAR}

A preocupação com a formação em nível superior de profissionais da gestão escolar iniciou, no Brasil, com a promulgação da Lei n. 5.692, de 11 de agosto de 1971, a qual exigia como formação mínima para assumir esses cargos curso de graduação, plena ou curta, ou curso de pós-graduação (BRASIL, 1971). No entanto, não especificava quais seriam esses cursos. Somente com a promulgação da Lei de Diretrizes e Bases da Educação Nacional n. 9.394, de 20 de dezembro de 1996, ficou determinado, no Art. 64, que:

\begin{abstract}
A formação de profissionais de educação para a administração, planejamento, inspeção, supervisão e orientação educacional para a educação básica será feita em cursos de graduaçáo em Pedagogia ou em nível de pós-graduação, a critério da instituição de ensino, garantida nesta formação, a base comum nacional (BRASIL, 1996).
\end{abstract}

Corroborando essa legislação, a Resolução CNE/CP n. 1, de 15 de maio de 2006, no Art. 5, define que o egresso do curso superior de Pedagogia, entre outras atribuiçóes, deverá estar apto a "participar da gestáo das instituiçôes contribuindo para elaboração, implementaçáo, coordenaçáo, acompanhamento e avaliação do projeto pedagógico" e demais projetos e programas educacionais. Para atender a essa formação, o curso prevê atividades práticas e de investigação em gestáo educacional, promovendo a "aplicação de princípios da gestão democrática em espaços escolares e não-escolares” (BRASIL, 2006).

Assim, a partir desses documentos legais elaborados pelo MEC, é possível verificar que os profissionais formados em cursos superiores de graduação em Pedagogia ou de pós-graduação estão habilitados para atuarem como diretores de escola, coordenadores pedagógicos, supervisores de ensino e orientadores educacionais.

De acordo com Bassi (2016), o diretor de escola é o "[...] líder do estabelecimento escolar, responde tanto pelas questôes legais como administrativas e pedagógicas". O coordenador pedagógico trata-se do "[...] articulador da dimensão pedagógica, tendo como responsabilidade a formação dos docentes". Já o supervisor de ensino deve "[...] apoiar e subsidiar todas as dimensóes, garantindo a efetivação das políticas públicas" (BASSI, 2016, p. 129). Enquanto o orientador educacional deve "[...] acompanhar todo o processo pedagógico e garantir um questionamento contínuo da prática de seu professor [...] Ele atua diretamente com professores, alunos e comunidade" (HASHIMOTO, 2016, p. 34).

Também, ficou evidente a importância que o MEC atribui à gestão democrática que deverá ser promovida por esses profissionais. Além disso, é válido destacar a importância dada à pós-graduação pelo MEC ao definir como uma das metas do Plano Nacional de Educação (PNE), em 2014, formar nesse nível de 
ensino 50\% dos professores da Educação Básica, até o último ano de vigência do plano (BRASIL, 2014).

\subsection{SOBRE A GESTÁO ESCOLAR DEMOCRÁTICA}

Lück (2009, p. 23) compreende gestão escolar como:

[...] uma das áreas de atuação profissional na educação destinada a realizar o planejamento, a organização, a liderança, a orientação, a mediação, a coordenação, o monitoramento e a avaliaçáo dos processos necessários à efetividade das açóes educacionais orientadas para a promoção da aprendizagem e formação dos alunos.

Desse modo, ficam evidentes as responsabilidades da gestáo escolar, que tem como foco principal a aprendizagem dos alunos. A autora classifica tais responsabilidades em administrativas e pedagógicas. As administrativas dizem respeito ao controle financeiro, de materiais e de recursos humanos, supervisão e orientação daqueles a quem são confiadas responsabilidades, e elaboração de normas e medidas a serem adotadas na instituição de ensino. Já as de cunho pedagógico referem-se ao suporte que deve ser dado aos membros da escola que buscam alcançar objetivos condizentes com os princípios educacionais, à liderança e inspiração no enriquecimento desses objetivos, e à estimulação para inovação e melhoria no processo educacional (LÜCK, 2001).

Para um gestor ser, de fato, democrático não basta apenas ser eleito pela comunidade escolar, composta por profissionais da educação, estudantes e seus responsáveis legais, mas sim permitir a participação deles nas tomadas de decisóes que envolvem o ambiente escolar. É por meio da interaçáo entre os diferentes agentes da gestão escolar e do seu trabalho coletivo que o espaço escolar vai adquirindo, no dia a dia, traços culturais e identidade (LIBÂNEO, 2013).

Essa ideia é da maior relevância, uma vez que, de acordo com Lück (2009): "A escola é uma organização social constituída pela sociedade para cultivar e transmitir valores sociais elevados e contribuir para a formação de seus alunos". Inclusive, na Lei de Diretrizes e Bases da Educação Nacional n. 9.394, Art. 12, inciso VI, é orientado que os estabelecimentos de ensino articulem-se "com as famílias e a comunidade, criando processos de integração da sociedade com a escola" (BRASIL, 1996).

A gestão democrática é defendida por diversos autores, entre eles, Abranches (2003). A autora afirma que, por meio da gestão democrática:

O colegiado pode, então, ser caracterizado como um órgão coletivo de decisôes, capaz de superar a prática do individualismo e do grupismo, instalando-se como uma instituição eminentemente política, na medida em que agrega de cada um dos setores (escola e comunidade) os seus interesses específicos, que devem ser unificados em prol do projeto da escola (ABRANCHES, 2003, p. 56). 
Paro (1997) alerta os diretores para refletirem que, ao compartilhar a gestáo entre os vários segmentos da escola, não perderão poder algum, mas sim dividirão responsabilidades. E, acontecendo isso, para o autor, quem ganha poder é a própria escola (PARO, 1997).

É na legislação que encontramos indicações de como pode-se operacionalizar a gestão democrática nas escolas. Na Lei de Diretrizes e Bases da Educação Nacional n. 9.394, Art. 14, são indicadas a "participação dos profissionais da educação na elaboração do projeto pedagógico da escola" e a "participação das comunidades escolar e local em conselhos escolares ou equivalentes" como princípios para a definição das normas de gestão democrática dos sistemas de ensino (BRASIL, 1996).

$\mathrm{Na}$ Resolução 4/2010, Art. 43, está definido que, mais do que um documento, o projeto político-pedagógico (PPP), possui autonomia pedagógica, administrativa e de gestão financeira interdependentes, e constitui-se "[...] um dos meios de viabilizar a escola democrática para todos e de qualidade social” (BRASIL, 2010). Analogamente, Gracindo (2004, p. 163) afirma que "[...] a democratização da escola e a existência de uma prática escolar democrática são instrumentos para a construção da cidadania, pode-se dizer que o projeto político-pedagógico é, por sua vez, um importante aliado na democratização mais ampla na sociedade”.

No PPP são descritos princípios e valores de educação que fundamentam as ações educativas realizadas na escola. Além disso, nesse documento são apresentadas as práticas pedagógicas da escola, os comportamentos permitidos e aqueles considerados atos de indisciplina, as funçôes de cada profissional, os horários de funcionamento da escola e de aula. Enfim, esse documento elaborado pelos profissionais da educação revela toda a organização da escola (BASSI, 2016).

Bassi (2016, p. 58) classifica o PPP em três dimensóes, a saber: dimensão pedagógica; dimensão administrativa; dimensão política. Para o autor, a dimensão pedagógica "[...] está relacionada ao plano de açôes que visa garantir que o currículo seja desenvolvido, levando os alunos ao pleno desenvolvimento das aprendizagens". Já a dimensão administrativa "[...] subsidia, favorece e fortalece o desenvolvimento da dimensão pedagógica". Enfim, a dimensão política "[...] relaciona-se com as demais, favorecendo as relaçóes entre todos envolvidos na comunidade escolar, com compromisso e responsabilidade social".

Com relação à participação da comunidade escolar e local, esta é viabilizada pelos principais órgãos colegiados comumente encontrados. São eles: o conselho escolar, a Associação de Pais e Mestres (APM) e o grêmio estudantil. O conselho escolar é composto por representantes de todos os segmentos da comunidade, isto é, professores, equipe diretiva, demais funcionários da escola, alunos e seus responsáveis legais. Já a APM é constituída, em maioria, por representantes legais de alunos e o corpo docente da escola. E o grêmio estudantil é formado somente por alunos (LIBÂNEO; OLIVEIRA; TOSCHI, 2003).

Vale ressaltar que, independente do meio utilizado para possibilitar a gestão escolar democrática, segundo Cury (2002, p. 173): "A gestão democrática 
da educação é, ao mesmo tempo, transparência e impessoalidade, autonomia e participação, liderança e trabalho coletivo, representatividade e competência. [...] Nesse sentido, a gestão democrática é uma gestão de autoridade compartilhada".

Enfim, como visto, gestão democrática trata-se de envolver a participação de todos os agentes da comunidade escolar - professores, demais profissionais da escola, alunos e seus responsáveis legais - na organização e administração escolar, "[...] de modo que a escola pode ser vista como um lugar de permanente aprendizagem. [...]", cujo processo é o foco principal de todos os objetivos educacionais (LIBÂNEO, 2013, p. 222).

\section{PROCEDIMENTOS METODOLÓGICOS}

Buscando responder ao problema "Quais são as dificuldades enfrentadas por alguns gestores na implementação da gestão democrática nas escolas onde atuam?" elaborou-se esta investigação de natureza aplicada, conforme proposto por Gil (1999), uma vez que aplica-se aos profissionais da educação que, ao realizarem sua leitura, poderão valer-se dos seus resultados para conscientizarem-se sobre a importância da gestão democrática para a escola e prepararem-se para as possíveis dificuldades que podem ser enfrentadas ao implementar essa modalidade de gestão escolar.

Quanto à abordagem do problema, selecionou-se a pesquisa qualitativa que é indicada nesse caso, pois suas variáveis, a saber, dificuldades enfrentadas na implementação da gestáo escolar democrática, não podem ser traduzidas em números. Ou seja, esta investigação é mais descritiva do ponto de vista dos seus objetivos (COLLIS; HUSSEY, 2005).

Para tanto, realizou-se um estudo de caso, pois, segundo Gil (1999), esse procedimento técnico abrange o estudo profundo de poucos objetos de modo a obter o seu amplo conhecimento, e esta investigação envolve a análise das respostas de apenas dez gestores escolares das redes municipal e estadual de ensino do Rio Grande do Sul a um questionário.

Os dados coletados foram analisados por meio da ATD, defendida por Moraes e Galiazzi (2011), perfazendo todas as suas etapas: unitarização; categorização; comunicação das novas compreensóes atingidas - metatexto. $\mathrm{Na}$ etapa de unitarização, as respostas dos gestores ao problema de pesquisa foram fragmentadas por unidades de significado, totalizando 13 fragmentos que foram codificados ${ }^{2}$. A seguir, na etapa de categorização, essas unidades foram agrupadas conforme semelhanças, emergindo assim três categorias de análise. Por fim, neste artigo, são apresentadas as novas compreensóes atingidas a partir dessa análise, concluindo assim o processo de ATD.

2 O número de fragmentos é superior ao número de sujeitos de pesquisa, pois, às vezes, de uma mesma resposta é possível obter duas ou mais unidades de significado que pertencerão a categorias de análise diferentes. 


\section{ANÁLISE DOS DADOS}

Os dados coletados para análise foram obtidos a partir das respostas de dez gestores escolares das redes municipal e estadual de ensino do Rio Grande do Sul a um questionário contendo o problema de pesquisa.

Primeiramente, cada resposta foi fragmentada em unidades de significado, as quais foram codificadas utilizando siglas que identificassem a qual sujeito de pesquisa elas pertenciam. Por exemplo, dois fragmentos do Gestor 8 analisados receberam as siglas G8.1 e G8.2, e dois fragmentos da resposta do Gestor 9 analisados receberam as siglas G9.1 e G9.2, e assim sucessivamente.

Após, as unidades foram agrupadas conforme similaridades de significado, emergindo, assim, três categorias de análise. Sáo elas: a falta de participação da comunidade escolar nas tomadas de decisóes referentes à escola (4 fragmentos), a falta de autonomia da escola devido à hierarquizaçáo da gestáo educacional (6 fragmentos) e a falta de atualização nas práticas pedagógicas dos professores e gestores (3 fragmentos).

Conforme já descrito, a Lei n. 9.394/1996 indica a participação de toda a comunidade escolar, incluindo pais, professores e funcionários, em conselhos escolares ou equivalentes. É por meio deste conselho que devem ser tomadas decisões relacionadas à escola, democraticamente, incluindo o uso de seus recursos financeiros e materiais (BRASIL, 1996). Entretanto, de acordo com a análise realizada, é possível verificar a falta de participação dos diversos agentes da comunidade escolar nas tomadas de decisóes referentes à escola. Cabe à equipe gestora, nesse caso, persistir na busca de meios que mobilizem o envolvimento de toda a comunidade escolar nas açôes e decisóes relativas à escola, como, por exemplo, feiras, gincanas, mutirôes, festividades, reunióes, assembleias, entrega de avaliações, entre outros.

Outra dificuldade enfrentada na implementação da gestão escolar democrática evidenciada na análise foi a falta de autonomia da escola devido à hierarquizaçáo da gestáo educacional, sendo essa a categoria emergente com o maior número de fragmentos agrupados. Nas respostas dadas ao questionário, é possível perceber que muitas vezes a escola acaba subordinada aos decretos da secretaria municipal ou estadual de educação e impossibilitada de realizar seus projetos individuais. Porém, é válido destacar, nesse caso, a importância dada pelo MEC à participação de todos os profissionais da educação na elaboração do PPP da sua respectiva escola, pois é esse importante documento que imprime a identidade da escola diante da sociedade e fundamenta as açóes que precisam ser realizadas nessa instituição de ensino em particular, com toda a autonomia pedagógica, administrativa e financeira que a legislação educacional brasileira lhe outorga (BRASIL, 1996; BRASIL, 2010).

Também emergiu nessa análise a preocupação dos gestores com a atualização das suas práticas pedagógicas e a de seus colegas professores, alegando que devem considerar o aluno como centro do processo de aprendizagem e, a partir disso, promover um ensino mais condizente com a realidade deles e com o avanço tecnológico ocorrido nos últimos anos em nossa sociedade. Acreditam que, assim, 
realizarão uma gestão pedagógica mais significativa. Uma possível solução para esse problema poderia ser a oferta de formação pedagógica para os gestores e professores pela mantenedora da escola ou, até mesmo, pela própria escola utilizando parte do seu capital adquirido autonomamente, desde que faça parte de projeto aprovado pela comunidade escolar e local anteriormente em conselho escolar ou equivalente de modo democrático. É válido, nesse caso, relembrar a importância dada à formaçáo continuada dos docentes pelo MEC ao definir como uma das metas do PNE, a ser atingida até o seu último ano de vigência, "formar, em nível de pós-graduação, $50 \%$ dos professores da Educação Básica", além de "[...] garantir a todos(as) os(as) profissionais da Educação Básica formação continuada em sua área de atuação, considerando as necessidades, demandas e contextualizaçôes dos sistemas de ensino" (BRASIL, 2014, p. 275).

Enfim, para sintetizar a análise das dificuldades enfrentadas por alguns gestores na implementação da gestáo democrática nas escolas onde atuam, elaborou-se o Quadro 1 que apresenta uma pequena amostra do modo como emergiram as três categorias de análise, apontando alguns fragmentos das respostas de cinco gestores, de um total de dez gestores.

Quadro 1 - Amostra do modo como emergiram as categorias de análise

\begin{tabular}{|c|c|c|c|}
\hline Gestor & Fragmento da resposta & $\begin{array}{l}\text { Unidade de } \\
\text { significado }\end{array}$ & $\begin{array}{l}\text { Categoria } \\
\text { emergente }\end{array}$ \\
\hline G3 & $\begin{array}{l}\text { G3.1 - "Dificuldade na participação dos pais, } \\
\text { professores e funcionários, perante a reuniōes/ } \\
\text { assembleias". }\end{array}$ & $\begin{array}{c}\text { Falta de } \\
\text { participação da } \\
\text { comunidade } \\
\text { escolar em } \\
\text { reunióes } \\
\end{array}$ & \multirow{2}{*}{$\begin{array}{l}\text { Falta de } \\
\text { participação da } \\
\text { comunidade escolar } \\
\text { nas tomadas de } \\
\text { decisóes referentes } \\
\text { à escola }\end{array}$} \\
\hline G5 & $\begin{array}{l}\text { G5.1 - "A grande dificuldade encontrada é a } \\
\text { falta de participação dos pais na escola para } \\
\text { a tomada de decisóes, bem como a falta de } \\
\text { colaboração de alguns profissionais da escola". }\end{array}$ & $\begin{array}{c}\text { Falta de } \\
\text { participação da } \\
\text { comunidade } \\
\text { escolar na tomada } \\
\text { de decisóes }\end{array}$ & \\
\hline G6 & $\begin{array}{l}\text { G6.1 - "Que a gestão da escola tenha autonomia } \\
\text { financeira, pedagógica e administrativa } \\
\text { suficiente para desenvolver seu trabalho". }\end{array}$ & $\begin{array}{c}\text { Falta de } \\
\text { autonomia } \\
\text { financeira, } \\
\text { pedagógica e } \\
\text { administrativa da } \\
\text { escola } \\
\end{array}$ & \multirow{2}{*}{$\begin{array}{l}\text { Falta de autonomia } \\
\text { da escola devido à } \\
\text { hierarquização da } \\
\text { gestão educacional }\end{array}$} \\
\hline G4 & $\begin{array}{l}\text { G4.1 - "Uma vez submetidos a uma hierarquia } \\
\text { organizada por políticos é muito improvável } \\
\text { que se consiga realizar uma gestáo democrática. } \\
\text { O que acontece na maior parte das vezes é em } \\
\text { reunióes chegarmos a um consenso direcionado } \\
\text { as ordens da mantenedora e interesses do } \\
\text { partido político a que estamos inseridos". }\end{array}$ & $\begin{array}{l}\text { Hierarquização da } \\
\text { gestáo estipulada } \\
\text { pela mantenedora } \\
\text { da escola }\end{array}$ & \\
\hline
\end{tabular}




\begin{tabular}{|c|c|c|c|}
\hline Gestor & \multicolumn{1}{|c|}{ Fragmento da resposta } & $\begin{array}{c}\text { Unidade de } \\
\text { significado }\end{array}$ & $\begin{array}{c}\text { Categoria } \\
\text { emergente }\end{array}$ \\
\hline \multirow{3}{*}{ G9 } & $\begin{array}{l}\text { G9.2 - "Fazer o professor ter uma abertura } \\
\text { para o novo alunado, para o mundo digital que } \\
\text { nos cerca, de realizar intervençóes pedagógicas } \\
\text { que possibilitem avanços significativos". }\end{array}$ & $\begin{array}{c}\text { Falta de } \\
\text { atualização } \\
\text { nas práticas } \\
\text { pedagógicas dos } \\
\text { professores }\end{array}$ & $\begin{array}{c}\text { Falta de atualizaçáo } \\
\text { nas práticas } \\
\text { pedagógicas dos } \\
\text { professores e } \\
\text { gestores }\end{array}$ \\
\hline
\end{tabular}

Fonte: Elaborado pelo autor (2020).

\section{CONSIDERAÇÓES FINAIS}

Ao finalizar esta investigação é possível apontar algumas consideraçôes sobre os resultados obtidos. No que se refere à definiçâo de gestáo escolar democrática, ficou evidente que trata-se do compartilhamento das açôes e tomadas de decisóes entre todos os agentes da comunidade escolar, sejam eles professores, demais profissionais da educaçáo, alunos e seus responsáveis legais, entre outros.

Evidenciou-se também que na legislação educacional brasileira constam alguns meios para promover a gestão escolar democrática, a saber, a elaboração do PPP da escola pelos seus profissionais da educação e, também, a constituição de conselhos escolares ou equivalentes pelos diversos agentes da comunidade escolar e local.

Conclui-se ainda que na busca pela implementação da gestão escolar democrática, os gestores, sujeitos desta pesquisa, se deparam com algumas dificuldades. Essas dificuldades, conforme verificado na análise dos dados, são a falta de participação da comunidade escolar nas tomadas de decisôes referentes à escola, a falta de autonomia da escola devido à hierarquizaçáo da gestão educacional e a falta de atualização nas práticas pedagógicas dos professores e gestores.

No entanto, vale destacar que, apesar das dificuldades encontradas na implementação da gestão escolar democrática, a democracia possui importância inegável na gestáo escolar. Assim, deve sempre ser promovida no ambiente educacional, pois a democracia é basilar para a convivência em sociedade, da qual a escola faz parte e para a qual a escola objetiva educar seus alunos.

\section{REFERÊNCIAS}

ABRANCHES, Mônica. Colegiado escolar: espaço de participação da comunidade. São Paulo: Cortez, 2003.

BASSI, Reginaldo A. O Projeto Político-Pedagógico e a Gestáo Escolar. Valinhos: 2016.

BRASIL. Ministério da Educação. Lei n. 5692, de 11 de agosto de 1971. Fixa diretrizes e bases para o ensino de $1^{\circ}$ e $2^{\circ}$ graus e dá outras providencias. Disponível em: <https:// www.planalto.gov.br/ccivil_03/leis/L5692.htm>. Acesso em: 18 dez. 2016. 
Ministério da Educação. Lei de Diretrizes e Bases da Educação Nacional no

9394, de 20 de dezembro de 1996. Estabelece as diretrizes e bases da educação nacional. Disponível em: <https://www.planalto.gov.br/ccivil_03/Leis/L9394.htm>. Acesso em: 18 dez. 2016.

. Ministério da Educação. Resolução CNE/CP no 1, de 15 de maio de 2006. Disponível em: <http://portal.mec.gov.br/cne/arquivos/pdf/rcp01_06.pdf>. Acesso em: 11 fev. 2013.

Ministério da Educação. Secretaria de Educação Básica. Resolução CNE/CEB no 4/2010. Diretrizes Curriculares Nacionais Gerais da Educação Básica. Disponível em: < http://portal.mec.gov.br/dmdocuments/rceb004_10.pdf>. Acesso em: 18 set. 2019.

. PLANO NACIONAL DE EDUCAÇÃO. Lei Federal no 13.005 de 2014.

Aprova o Plano Nacional de Educação - PNE e dá outras providências.

COLLIS, Jill; HUSSEY, Roger. Pesquisa em administração: um guia prático para alunos de graduação e pós-graduação. 2. ed. Porto Alegre: Bookman, 2005.

CURY, Carlos Jamil. Gestão Democrática da Educação: exigências e desafios. Revista Brasileira de Política e Administraçáo da Educação. Porto Alegre: ANPAE, v. 18, n. 2, p. 30-45, out. 2002 .

GESTÃO. In: DICIO, Dicionário Online de Português. Porto: 7Graus, 2020. Disponível em: https://www.dicio.com.br/gestao/. Acesso em: 24/04/2020.

GIL, Antônio Carlos. Métodos e técnicas em pesquisa social. 5. ed. São Paulo: Atlas, 1999.

GRACINDO, Regina V. Projeto político-pedagógico: retrato da escola em movimento, In: SILVA, A. M.; AGUIAR, M. A. (Orgs.). Retrato da escola no Brasil. Brasília: CNTE, 2004, p. 27-42.

HASHIMOTO, Cecília I. A gestáo e a organizaçáo do trabalho pedagógico. Valinhos, 2016.

LIBÂNEO, José Carlos. Organização e gestão da escola: Teoria e Prática. 6. ed. São Paulo: Heccus Editora, 2013.

.; OLIVEIRA, João Ferreira; TOSCHI, Mirza Seabra. Educação escolar: políticas, estrutura e organização. 2. ed. São Paulo: Cortez, 2003.

LÜCK, Heloísa. Ação integrada: administração, supervisão e orientação educacional. 18. ed. Petrópolis/RJ: Vozes, 2001.

Dimensóes de gestáo e suas competências. Curitiba: Editora Positivo, 2009.

MINICUCCI, Agostinho. Relaçóes humanas: psicologia das relaçóes interpessoais. 6. ed. São Paulo: Atlas, 2001. 
MORAES, Roque; GALIAZZI, Maria do Carmo. Análise textual discursiva. 2. ed. rev. Ijuí: Unijuí, 2011.

PARO, Vitor Henrique. Administração Escolar: introdução crítica. 3. ed. São Paulo: Cortez, 1988.

. Gestáo democrática da escola pública. São Paulo: Ática, 1997. 